\title{
Kemampuan Mitigasi dan Kapasitas Resiko Gempa Bumi Pada Mahasiswa Magister IPA Universitas Mataram
}

\author{
Kosim Kosim $^{1 *}$, Muhamad Makhrus ${ }^{1}$, Aliefman Hakim² \\ ${ }^{1}$ Prodi pendidikan Fisika, Universitas Mataram, Mataram, Indonesia ; \\ ${ }^{2}$ Prodi pendidikan Kimia, Universitas Mataram, Mataram, Indonesia ;
}

DOI: https://doi.org/10.29303/.jpmsi.v2i2.86

Citation: Kosim, K., Makhrus, M., Hakim, A. 2020. Kemampuan Mitigasi dan Kapasitas Resiko Gempa Bumi pada Mahasiswa Magister IPA Universitas Mataram. Jurnal Pengabdian Masyarakat Sains Indonesia (JPMSI). 2(2):177180 .

Article history

Received: November $20^{\text {th }} 2020$

Revised: November $30^{\text {th }} 2020$

Accepted: December $28^{\text {th }} 2020$

*Corresponding Author:

Kosim Kosim,Universitas

Mataram, Indonesia

Email:

kosim_fisika@unram.ac.id

\begin{abstract}
Abstrak: Bencana Gempa Bumi tak dapat diprediksi kapan kejadiannya dan seberapa besar resiko bahaya yang akan ditimbulkannya. Manusia hanya bisa berbuat bagaimana mengurangi/memperkecil resiko kerusakan akibat bencana dengan melakukan tindakan mitigasi yaitu mempersiapkan apa yang mesti dilakukan sebelum, sesaat dan pasca bencana. Melalui sosialisasi kapasitas pengurangan resiko kebencanan dan mitigasi bencana pada mahasiswa Magister IPA, diharapkan informasi pengetahuan kebencanaan akan tersebar ke masyarakat yang lebih luas. Berdasarkan kegiatan tersebut telah disebarkan quis pengetahuan kebencanaan melalui google form dan terkumpul data sebanyak 45 partisipan mengenai kemampuan kognitif mitigasi dan kapasitas resiko kebencanaan. Hasil menunjukkan kemampuan kognitif peserta relatif sedang. Artinya pengetahuan yang berhubungan dengan ini perlu desiminasi.
\end{abstract}

Kata kunci: mitigasi bencana, kapasitas resiko gempa bumi.

\section{Pendahuluan}

Berdasarkan pengetahuan ilmu geologi dan geofisika, memang Indonesia berada pada daerah " ring of fire", dimana rangkaian gunung berapi menyebar di pulau-pulau Indonesia. Selain itu Indonesia juga berada pada wilayah diantara 3 zone lempeng tektonik yang selalu menimbulkan pergerakan penyebab terjadinya gempa bumi tektonik.

Sebagaimana telah dirasakan bersama oleh masyarakat Lombok khususnya dampak dari bahaya bencana alam gempa bumi yang terjadi tahun 2018, menimbulkan banyak korban. Update terakhir jumlah korban jiwa menurut laporan BNPB 17 Agustus 2018 adalah 481 orang meninggal dunia dan 1413 orang luka-luka. Jumlah yang harus diungsikan baik laki-laki maupun perempuan dari lokasi bencana ke tempat aman sekitar 431.414 orang (https://www.bnpb.go.id/indonesia-gempabumilombok ).

Data tersebut baru menunjukan kerugian korban jiwa, belum kerugian kerusakan harta benda. Berdasarkan laporan untuk menanggulangi gempa Lombok, menteri keuangan Sri Mulayani telah mencairkan Rp 985,8 miliar yang terdiri dari Rp 557,7 miliar melalui BNPB dan sebesar Rp 428,1 miliar melalui Kementerian/Lembaga, seperti kementrian PUPR dan kementerian Kesehatan (https://republika.co.id/berita/, kamis 23 Agustus 2018).

Berdasarkan data dan informasi diatas, alangkah baiknya masyarakat NTB memiliki pengetahuan dan keterampilan yang berhubungan dengan mitigasi bencana. Upaya penyadaran dan sosialisasi melalui sekolah di NTB berhubungan dengan mitigasi bencana telah dilakukan sesuai tulisan artikel Syahrial dkk (2019), Kosim dkk (2019) I Wayan Gunada dkk (2020) dan Syahrial dkk (2020). Mahasiswa yang merupakan bagian dari masyarakat intelek, perlu menjadi garda terdepan dalam upaya menyebarkan informasi pengetahuan kebencanaan dalam upaya pengurangan resiko yang diakibatkan bencana alam 
Kosim et al, Jurnal Pengabdian Masyarakat Sains Indonesia 2020, 2 (2):177-180. DOI : https://doi.org/10.29303/jpmsi.v2i2.86

tersebut. Berhubungan dengan tugas mengajar di Magister IPA, maka timbullah pertanyaan terhadap kemampuan kognitif mahasiswa Magister IPA pada mitigasi bencana alam.

\section{Metode}

Pengumpulan data dilakukan dengan mengirimkan quesionare googleform kepada responden ( mahasiswa magister IPA-Universitas mataram) melalui WA grup, e-mail dan juga saat pertemuan dalam zoom meeting. Data yang di isi oleh responden langsung tersimpan di google drive milik kosim fisika@unram.ac.id.

Dalam kegiatan zoom meeting telah dipresntasikan 3 sesion yang mendukung tema judul penyuluhanpengabdian. Presentasi Power point terdiri dari A) Pengetahuan Kebencanaan dan dampaknya, B). Kapasitas Pengurangan Resiko Kebencanaan dan C) Siaga Bencana. Peserta zoom meeting diberi kesempatan untuk bertanya. Dalam selang pergantian sesion diputarkan video pendek berhubungan dengan pengetahuan kebencanan dengan durasi maksimum 5 menit. Bukti kegiatan zoom meeting ditampilkan dalam gambar 1 berikut ini. Selain itu saat zoom meeting berlangsung dikirimkan pula absensi kegiatan yang diisi oleh responden dan langsung tersimpan dialamat yang telah disebutkan diatas. Dalam kegiatan tersebut, kami memberikan pengahargaan kepada responden dengan memberikan sertifikat ke ikutsertaan dalam penyuluhan tersebut.

Berselang beberapa hari setelah kegiatan zoom meeting, responden peserta zoom meeting dikirimi lagi quesionare yang sama. Semua data yang terkumpul di olah dan dinalisa. Pengolahan terhadap data responden di dapat mengenai jumlah peserta zoom meeting, alamat tinggal mahasiswa dan jenis kelamin. Sedangkan untuk mengetahui klasifikasi tingkat penguasaan pengetahuan responden mengacu pada kriteria tabel 2 . berikut ini:

Tabel 2. Kriteria Peringkat Penguasaan Pengetahuan

\begin{tabular}{ccl}
\hline Tingkat & \multicolumn{1}{c}{ Kriteria } & \multicolumn{1}{c}{ Keterangan } \\
\hline Tinggi & $\ldots \ldots \ldots \ldots \ldots \ldots \ldots \ldots$ MI+0,5SDI & $\begin{array}{l}\text { MI }=(1 / 2) \\
(\mathrm{Xmax}+\mathrm{Xmin})\end{array}$ \\
Cukup & MI-0,5SDI s/d MI+0,5SDI & $\begin{array}{l}\text { SDI }=(1 / 6) \\
(\mathrm{Xmax}-\mathrm{Xmin})\end{array}$ \\
Kurang & $\ldots \ldots \ldots \ldots \ldots \ldots . . . \mathrm{MI}-0,5$ SDI & \\
\hline
\end{tabular}

(Riduwan, 2010)
e-ISSN : 2715-2537

p-ISSN : 2715-2545

Dalam pengolahan data ini di analisa juga terhadap prosentase penguasaan pengetahuan kebencanaan, Kapasitas Resiko kebencanaan dan Mitigasi bencana.

\section{Hasil dan Pembahasan}

Berdasarkan hasil pengumpulan dan pengolahan data, diperoleh bahwa peserta penyuluhan peningkatan pengetahuan dan kapasitas pengurangan resiko kebencanaan pada mahasiswa magister IPA universitas mataram telah di ikuti oleh 45 peserta. Mereka terdiri dari 29 putri dan 16 putra, sebagaimana ditunjukkan pada gambar 1 .

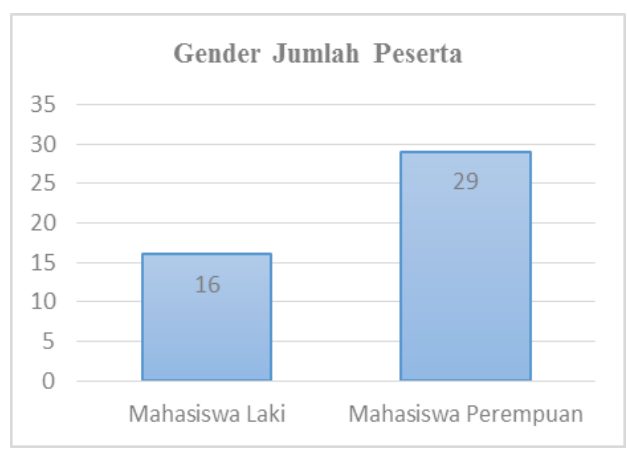

Gambar 1. Grafik gender jumlah peserta

Adapun berdasarkan asal tempat tinggal responden, ditunjukkan pada gambar 2 berikut ini.

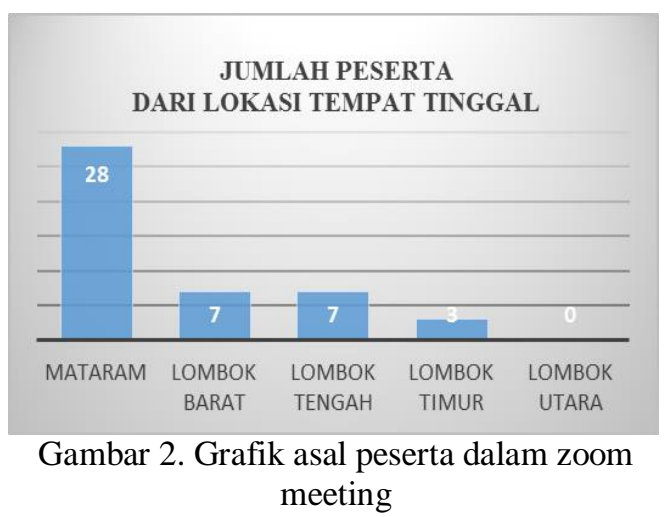

Peserta penyuluhan didominasi dari wilayah Mataram ada 28 orang, kemudian dari Lombok Barat dan Lombok Timur masing-masing 7 orang. Peserta dari Lombok Timur 3 orang, sedangkan dari Lombok Utara tidak ada pesertanya. 
Kosim et al, Jurnal Pengabdian Masyarakat Sains Indonesia 2020, 2 (2):177-180. DOI : https://doi.org/10.29303/jpmsi.v2i2.86

Pembahasan terhadap penguasaan pengetahuan dan kapasitas pengurangan resiko bencana pada peserta penyuluhan melalui zoom meeting dan telah dianalisa berdasarkan kriteria tingghi, cukup dan kurang menurut Riduwan (2010) dimana Mean Ideal $(\mathrm{DI})=66,5$ dan Standar Deviasi Ideal $(\mathrm{SDI})=9,0$ ditunjukkan oleh grafik pada gambar 3.

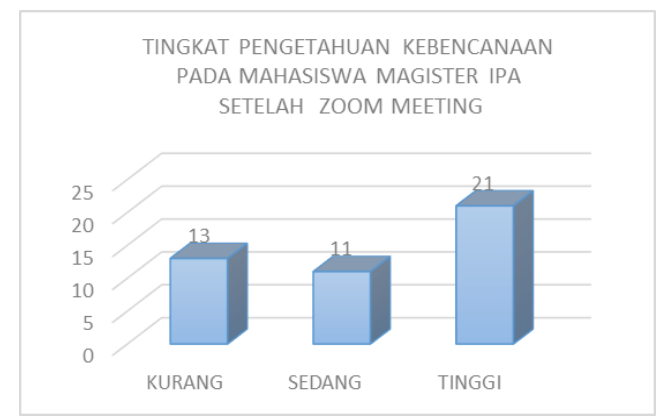

Gambar 3. Grafik Tingkat Pengetahuan

Pada gambar 3 menunjukkan bahwa tingkat pengetahuan peserta penyuluhan untuk pengetahuan kebencanaan 21 orang berada di level tinggi, artinya nilai mereka di atas nilai rata- rata ideal. Akan tetapi jika dibandingkan dengan jumlah keseluruhan, maka yang berada di nilai tinggi kurang setengahnya, yaitu 46,7 \% dari seluruh peserta.

Jika analisa lebih dalam dilakukan terhadap materi presentasi sesuai quosioner, diperoleh prosentase data terhadap penguasaan pengetahuan kebencanaan, kapasitas dan mitigasi bencana seperti yang ditunjukkan gambar 4 .

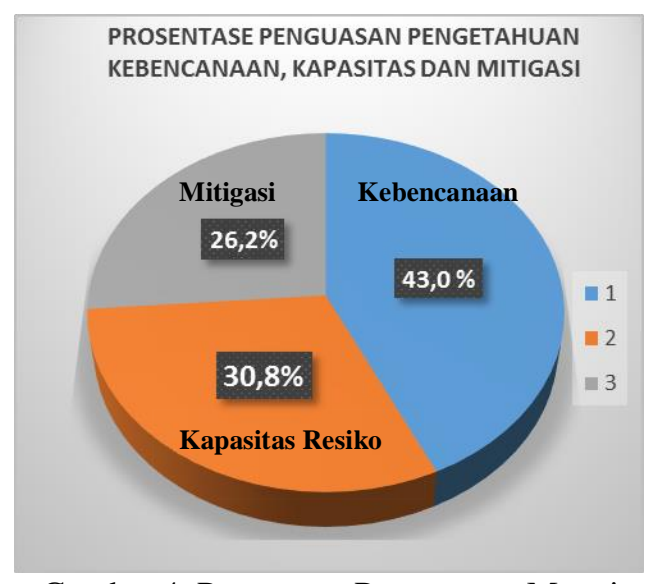

Gambar 4. Prosentase Penguasaan Materi

Mengacu pada gambar 4, bahwa penguasaan materi Kebencanaan mendapatkan porsi yang lebih besar, karena hal ini sudah terbiasa
e-ISSN : 2715-2537

p-ISSN : 2715-2545

dalam literatur. Berbeda dengan pengetahuan kapasitas dan mitigasi. Nampaknya bahwa memang benar mitigasi itu harus bisa dipraktekan atau disimulasikan secara langsung agar mudah di ingat.

Berbagai upaya Mitigasi kebencanaan diperkenalkan kepada masyarakat. Ningtyas dan Duana (2018) telah mempraktekan kegiatan mitigasi bencana gempa bumi pada anak usia dini. Syahrial dkk (2019) telah melatih siswa SMP untuk simulasi kesiap siagaan terhadap gempa bumi dilingkungan sekolah. Kosim (2019) dalam laporannya telah melakukan pelatihan disaster mitigation and planing di Jepang bersama 25 anggota dari Indonesia selama 12 hari. Praktek pelatihan telah terbit beerbagai panduan diantaranya yang diterbitkan oleh PNBP (2017) tentang latihan kesiapsiagaan bencana.

Dalam upaya peningkatan kapasitas pengurangan resiko bencana telah banyak artikel yang terbit diantaranya Srewil (2008), Des Marais et all (2012), Paul and Shatosi (2014). Begitu juga peneliti dari Indonesia yang meneliti berkaitan dengan kapasitas resiko kebencanaan seperti Wahyuni dkk (2015) dan Susilowati dan Lilik (2016). Pihak pemerintahpun melalui BNPB (2012) telah mengeluarkan aturan tentang peningkatan kapasitas masyarakat dalam mengurangi resiko bencana.

Pada intinya semua kegiatan yang dapat menyelamatkan dan mengurangi dampak akibat bencana alam harus terus dilakukan. Artinya manusia diwajibkan untuk terus berusaha, walaupun keputusan akhir ada pada Tuhan Yang Maha Kuasa.

\section{Kesimpulan}

Berdasarkan hasil dan pemahasan diatas nampak jelas dapat dismpulkan bahwa :

1. Kegiatan penyuluhan ini cukup direspon baik oleh responden mahasiswa Magister pendidikan IPA

2. Penyuluhan melalui Zoom meeting telah dapat mendeskripsikan bahwa 46,7 \% peserta berada pada level pengetahuan kebencana yang baik/ tinggi

3. Pengetahuan yang berhubungan dengan Mitigasi masih menduduki prosentase terendah yang dikuasai oleh responden. 
Kosim et al, Jurnal Pengabdian Masyarakat Sains Indonesia 2020, 2 (2):177-180. DOI : https://doi.org/10.29303/jpmsi.v2i2.86

\section{Saran}

Saran-saran yang dapat disampaikan dalam kesempatan ini adalah :

1. Penyuluhan yang berhubungan dengan mitigasi kebencanaan sebaiknya tidak melalui zoom meeting, melainkan langsung bertatap muka dan melakukan simulasi tindakan mitigasi kebencanaan.

2. Kehadiran peserta zoom meeting belum bisa di jamin bahwa mereka benar benar hadir di depan layar, sehubungan video wajah (life) peserta banyak yang tidak dimunculkan.

\section{Ucapan Terima Kasih}

Penulis mengucapkan terima kasih kepada Prodi Magister IPA Pascasarjana Universitas Mataram dan juga LPPM Unram yang telah memberi dukungan financial terhadap kegiatan pengabdian masyarakat. Terimakasih pula kepada mahasiswa Magister IPA Universitas yang telah berpartisifasi dalam kegiatan ini.

\section{Daftar Pustaka}

BNPB. 2012. Peraturan Kepala Badan Nasional Penanggulangan Bencana Nomor 2 Tahun 2012 tentang Pendoman Umum Pengkajian Risiko Bencana.

Des Marais, E.A., Bhadra, S. and Dyer, A.R. 2012. In the wake of Japan's Triple Disaster: Rebuilding capacitythrough international collaboration. Adv. Soc. Work. 3, 340-357

I Wayan Gunada, Syahrial Ayub, Aris Doyan, Muhammad Taufik dan Kosim. 2020. Development of Disaster Mitigation Learning Structures. Jurnal Penelitian Pendidikan IPA. DOI: 10.29303 /jppipa.v6i1.324, Vol.6(1). pp.69-74.

Kosim, Kosim, Syahrial.A, I.Wayan Gunada and Endang P.handayani (2019).Audio Visual Based Learning on Landslide and Tsunami Mitigation infith Grade Students at State Primary School (SDN) 6 Mataram. Proceedings of the 1st Annual Conference on Education and Social Sciences. Atlantis Press. Vol. 465.

Paul Ofei-Manu and Shatosi Simato,.2014. Disaster Risk Reduction Capacity Assessment: Reflecting on the Japanese Experience,
e-ISSN : 2715-2537

p-ISSN : 2715-2545

Institute for Global Environmental Strategies (IGES), Hayama, Japan. P. 5766.

Riduwan. 2010. Dasar-Dasar Statistika. Alfa Beta. Bandung.

Susilowati, Fitri dan Lilik Siswanta. 2016. Peningkatan Kapasitas Masyarakat Dalam Menghadapi Risiko Bencana Berbasis Gender . Jurnal SEMAR, ISSN 2302-3937 . vol 5 no.1.p. 41-49.

Syahrial, A. Muhammad Makhrus, Jannatin Arduha,Ni Nyoman Sri Putu Verawati, Kosim. 2019. Kesiapsiagaan Bencana Gempabumi di SMP Negeri 2 Mataram. Prosiding PEPADU Seminar Nasional Pengabdian pada Masyarakat Universitas Mataram, e-ISSN: 2715-5811, Vol. 1, 2019

Syahrial A, Kosim, I Wayan Gunada, Endang P Handayani. 2020. Kesadaran kebencanaan Pada Prilaku Kesiapsiagaan Siswa. Jurnal ORBITA, Volume 6, Nomor 2, p-ISSN : 2460-9587 e-ISSN : 2614-7017

Wahyuni, Eldina Fatimah dan Azmeri. 2015. Analisis

Tingkat Kerentanan Dan Kapasitas Masyarakat Terhadap Bencana Banjir Bandang Kecamatan Celala Kabupaten Aceh Tengah. Jurnal Ilmu Kebencanaan . Pascasarjana Universitas Syiah Kuala. ISSN 2355-3324 .Vol.2 No.3. p.33-40 